\title{
Intra-cervical foley's catheter or PGE2 gel for induction of labour: which one is better: a prospective study
}

\author{
Khushpreet Kaur ${ }^{1}$, Balwinder Kaur ${ }^{1}$, Navneet Kaur ${ }^{1 *}$, Gagandeep Kaur ${ }^{2}$
}

\begin{abstract}
${ }^{1}$ Department of Obstetrics and Gynecology, Govternment Medical College, Patiala, Punjab, India
${ }^{2}$ Civil Hospital, Barnala, Punjab, India
\end{abstract}

Received: 20 March 2021

Revised: 05 April 2021

Accepted: 06 April 2021

\author{
*Correspondence: \\ Dr. Navneet Kaur, \\ E-mail: nav_neetu8@yahoo.in
}

Copyright: (C) the author(s), publisher and licensee Medip Academy. This is an open-access article distributed under the terms of the Creative Commons Attribution Non-Commercial License, which permits unrestricted non-commercial use, distribution, and reproduction in any medium, provided the original work is properly cited.

\begin{abstract}
Background: Labour is clinically defined as the initiation and perpetuation of uterine contraction with goal of producing progressive cervical effacement and dilatation. The Foley's catheter is an effective alternative to prostaglandins for cervical ripening/labour induction. Study was done to compare the efficacy of intracervical Foley's catheter and PGE2 gel as a cervical ripening agent and to study maternal and fetal outcome in terms of mode of delivery and Apgar score.

Methods: This randomized controlled study was conducted in Obstetrics and Gynaecology department, Government Medical College, Patiala. 200 women with indication for induction of labour were enrolled in the study to investigate the efficacy and fetomaternal outcome of induction of labour with intracervical Foley's catheter comparing with PGE2 gel.

Results: The mean age in group A was $24.41 \pm 3.37$ and in group B was $24.24 \pm 3.17$ years. The $95 \%$ women were induced successfully in group A and $97 \%$ were successfully induced in group B. Preeclampsia and postdatism were the most common indications for induction in both groups. The mean induction delivery interval in group A was 15.20 \pm 4.53 hours and in group B was $15.86 \pm 4.79$ hours. $4.21 \%$ cases required NICU admission in group A while in group B, it was $5.15 \%$ cases.

Conclusions: Our study concludes that there is no difference in efficacy between intracervical Foley's catheter and intracervical PGE2 gel for induction of labour and both methods are complementary to each other.
\end{abstract}

Keywords: Labour, Foley’s catheter, PGE2 gel, Vaginal delivery, Caesarean

\section{INTRODUCTION}

Normal labour is the presence of regular uterine contractions that results in effacement and dilatation of cervix with voluntary bearing down efforts leading to expulsion of the products of conception per vaginum. ${ }^{1}$

Labour is clinically defined as the initiation and perpetuation of uterine contraction with goal of producing progressive cervical effacement and dilatation. Induction of labour refers to the process whereby uterine contractions (>3 in 10 mins each lasting for 30-45 seconds), cervical softening and effacement are initiated by medical or surgical means before the onset of spontaneous labour. 50\% of inductions in Asian facilities are elective, highest being in Sri Lanka (77.2\%). This is followed by Thailand (44.6\%), Japan (41.0\%), India $(32.1 \%)$ and China (20.4\%), lowest rate of induction of labour is in African countries, Nigerian being having lowest rate of $1.4 \%$. The rate of elective inductions are increasing nowadays. According to ACOG, one fifth of all pregnancies are terminated with various methods of induction. $^{2}$

Low bishop scores are associated with increased risk of cesarean delivery. Other factors that increase the risk of 
cesarean section after induction include nulliparity, obesity, maternal age greater than 30 years, fetal macrosomia, use of epidural anesthesia, use of magnesium sulfate, and chorioamnionitis.

Success of induced labour depends upon the degree of ripening of cervix which can be assessed by various scoring systems and the most commonly used method is Bishop scoring which includes cervical dilatation, length of cervix, consistency of cervix, position of cervix and station of presenting part. The total score is 13 and favourable score is 6-13. ${ }^{8}$ It was modified in 1982 and effacement was considered by cervical length in centimeters instead of percentage.

The various methods of methods of induction of labour are: mechanical, surgical, pharmacological and combined methods.

\section{Transcervical Foley's Catheter}

It is a mechanical method and its effect on cervical ripening was first described by Embrey and Mollison in 1967. The Mechanical action of Foley's Catheter strips the foetal membranes from the lower uterine segment which causes release of phospholipase A2, prostaglandins, and cytokines which are associated with cervical dilatation. ${ }^{9}$

The ACOG (2009) guidelines recommend the Foley's catheter as a sensible and effective alternative to prostaglandins for cervical ripening/labour induction (grade A recommendation). Its use is mentioned as an option for outpatient induction.

According to WHO, recommendations (2011) balloon catheters are recommended for labour induction and are approximately as efficient as vaginal prostaglandins (PGE2, misoprostol).

The combination of balloon catheter and oxytocin is recommended as an alternative when prostaglandins (including misoprostol) are not available or are contraindicated. The balloon catheter is also mentioned as an option for labour induction after previous caesarean section. ${ }^{12}$

The surgical method of induction includes stripping of membranes and fore water amniotomy (Artificial rupture of membranes). The pharmacological methods are prostaglandins, mifepristone, oxytocin and relaxin.

The mechanical devices result only in cervical dilatation and the PG agents both soften and efface the cervix but the combination of the two methods may result in a greater degree of cervix ripening and successful labour induction.

The aim and objective of the study was to compare the efficacy of intracervical Foley's Catheter and PGE2 gel as a cervical ripening agent, to study maternal and fetal outcome in terms of mode of delivery and Apgar score.

\section{METHODS}

The present randomized controlled study was conducted in Department of Obstetrics and Gynaecology, Government Medical College, Rajindra Hospital Patiala from January 2017 to 2018. 200 women with indication for induction of labour were enrolled in the study after fulfilling the inclusion and exclusion criteria. The proper counselling was done and written informed consent was taken. It was carried out to investigate the safety, efficacy and fetomaternal outcome of induction of labour with intacervical Foley's Catheter comparing with the commonly used agent PGE2 gel. Patients admitted to labour room for induction of labour were enrolled for study. After written and informed consent, 200 women were assigned randomly into 2 groups fulfilling the inclusion and exclusion criteria after proper counselling and clinical assessment. Particulars of the patient and detailed history as per proforma was recorded. A thorough general physical examination and systemic examination was done to exclude any maternal disease. Obstetrical examination and vaginal examination was done to assign Bishop's score and for pelvic assessment.

GROUP A-100 patients were inserted intracervical Foley's catheter. Under aseptic precaution $16 \mathrm{~F}$ foley's catheter was introduced beyond the internal OS and its balloon was inflated with 30-60 ml sterile water. Traction was applied by taping the distal end of the catheter with medial aspect of the thigh. Catheter was checked for its position and traction at 4-6 hours interval. Intracervical catheter was removed after 24 hours if it doesn't get expelled.

GROUP B-100 patients were given $0.5 \mathrm{mg}$ PGE2 gel under fully aseptic conditions. PGE2 Gel was inserted intracervically while patient in lithotomy position and patient was told to lie down for $30 \mathrm{~min}$. Assessment of bishop's score was done, dose was repeated if required when patient was reassessed after 12 hours and again at 24 hours.

\section{Inclusion criteria}

Gestation age of 37 weeks or more, bishop <6, singleton pregnancy, cephalic presentation, intact membranes, primigravida/multigravida and women's willingness.

\section{Exclusion criteria}

Previous uterine surgery, antepartum hemorrhage, allergy to prostaglandins, CPD and woman's unwillingness.

\section{Statistical analysis}

The collected data was compiled and analysed statistically statistical analysis was performed using Chi square statistics and compared. IBM Software Excel and statistical Package for Social Sciences (SPSS) version 22 was used. 


\section{RESULTS}

The maximum number of subjects were in age group of 21-25 years in both the study groups. The mean age in group A was $24.41 \pm 3.37$ and in group B was $24.24 \pm 3.17$ years. The $\mathrm{p}$ value was 0.714 which was statistically not significant (Table 1). $72 \%$ patients were primigravida and $28 \%$ were multigravida in group A and $58 \%$ patients were primigravida and $42 \%$ were multigravida in group B. The $\mathrm{p}$ value was 0.492 which was not significant (Table 1). According to the modified kuppuswamy scale, majority of the patients were from lower socioeconomic status, $(54 \%)$ in group A and $48 \%$ in group B. Its p value was 0.177 which was again not significant (Table 1). The mean gestation age was $39.39 \pm 1.73$ weeks in group A and it was $39.62 \pm 1.74$ in group B. The subject in both the groups were almost equally distributed and $\mathrm{p}$ value was 0.356 which was not significant (Table 1). Preeclampsia was the most common indication for induction of labour in group A $(40 \%)$ while postdatism was most common in group B (33\%). Second most common indication was postdated pregnancy in group A in $29 \%$ cases and in group B, it was preeclampsia (32\%) (Table 2).

Table 1: Maternal characteristics.

\begin{tabular}{|c|c|c|c|c|c|}
\hline Characteristics & \multicolumn{2}{|c|}{ Group A } & \multicolumn{2}{|c|}{ Group B } & \multirow{2}{*}{ P value } \\
\hline Age (years) & Patients & $\%$ & Patients & $\%$ & \\
\hline $16-20$ & 7 & 7 & 15 & 15 & \multirow{5}{*}{$\begin{array}{l}0.714 \\
\text { Not significant } \\
\text { (NS) }\end{array}$} \\
\hline $21-25$ & 63 & 63 & 54 & 54 & \\
\hline $26-30$ & 24 & 24 & 27 & 27 & \\
\hline $31-35$ & 6 & 6 & 4 & 4 & \\
\hline Mean \pm SD & \multicolumn{2}{|c|}{$24.41 \pm 3.37$} & \multicolumn{2}{|c|}{$24.24 \pm 3.17$} & \\
\hline \multicolumn{5}{|l|}{ Parity } & \multirow{3}{*}{$\begin{array}{l}0.492 \\
\text { NS }\end{array}$} \\
\hline Primigravida & 72 & 72 & $58 \%$ & 58 & \\
\hline Multigravida & 28 & 28 & 42 & 42 & \\
\hline \multicolumn{5}{|c|}{ Socioeconomic status } & \multirow{4}{*}{$\begin{array}{l}0.177 \\
\text { NS }\end{array}$} \\
\hline Lower & 54 & 54 & 48 & 48 & \\
\hline Middle & 44 & 44 & 45 & 45 & \\
\hline Higher & 2 & 2 & 7 & 7 & \\
\hline
\end{tabular}

Table 2: Indication for induction of labour.

\begin{tabular}{|lllll|}
\hline Indication for induction & Group A & Group B \\
\hline Antepartum eclampsia & Patients & $\mathbf{\%}$ & Patients & \% \\
\hline Congenital anomaly & 8 & 8 & 11 & 11 \\
\hline Derranged colour doppler & 1 & 1 & 4 & 4 \\
\hline Fetal growth restriction & 4 & 4 & 3 & 3 \\
\hline Gestational diabetes mellitus & 5 & 5 & 6 & 6 \\
\hline Intrahepatic Cholestasis of Pregnancy & 2 & 2 & 1 & 1 \\
\hline Intrauterine-fetal death & 1 & 1 & 0 & 0 \\
\hline Oligohydraminos & 4 & 4 & 6 & 6 \\
\hline Post datism & 5 & 5 & 4 & 4 \\
\hline Pre-eclampsia & 29 & 29 & 33 & 33 \\
\hline Polyhydramnios & 40 & 40 & 32 & 32 \\
\hline
\end{tabular}

The $95 \%$ women were induced successfully in group A and $97 \%$ were successfully induced in group B. $5 \%$ women in group A and 3\% in group B had failed induction and all of them underwent caesarean section. The $p$ value was 0.46 and it was statistically not significant (Table 3). Among 95 women who had successful induction, 84.21\% had vaginal delivery while $15.79 \%$ underwent caesarean section due to fetal distress, meconium stained liquor or no-progress of labour. In group $\mathrm{B}$, vaginal delivery occurred in $79.38 \%$ cases and $20.62 \%$ landed up caesarean section despite good uterine contractions due to fetal distress or meconium stained liquor or non-progress of labour. The $\mathrm{p}$ value was 0.486 which was not significant (Table 3). In group A, about $28.42 \%$ of subjects delivered in less than 12 hours and in group B, $26.80 \%$ delivered in less than 12 hours. The mean induction delivery interval in group A was $15.20 \pm 4.53$ hours and $15.86 \pm 4.79$ hours. The $\mathrm{p}$ value was 0.352 and it was statistically not significant (Table 3). The most common indication for LSCS in both the groups was fetal distress $(40 \%)$. The other common indication for caesarean section was $26.6 \%$ and $35 \%$ in both the groups respectively due to meconium stained liquor (Table 4). Hypertonicity was observed in $2.04 \%$ of cases in group A and in $6.06 \%$ in group B. Postpartum 
haemorrhage, shivering, nausea, vomiting and infections are some of the other less common complications encountered. (Table 4). $6.32 \%$ of the neonates in group A faced fetal distress and in group B, it was $8.25 \% .4 .21 \%$ of the newborn in group A had neonatal jaundice whereas in group B, it was $3.09 \%$. Almost $2 \%$ newborns in both the groups had meconium aspiration syndrome. $4.21 \%$ cases required NICU admission in group A while in group B, it was $5.15 \%$ cases. The p-value was 0.238 and it was statistically not significant (Table 5). APGAR $<7$ at 1 minute was $5.2 \%$ in group A and $7.2 \%$ in group B and pvalue was 0.576 which was not significant. The APGAR $<7$ at 5 minutes in group A was $2.1 \%$ and in $3.09 \%$ in group B. Its p-value was 0.676 and it was statistically not significant (Table5).

Table 3: Results of induction.

\begin{tabular}{|c|c|c|c|c|c|}
\hline Characteristics & \multicolumn{2}{|c|}{ Group A } & \multicolumn{2}{|c|}{ Group B } & P value \\
\hline Results & Patients & $\%$ & Patients & $\%$ & \\
\hline Successful induction & 95 & 95 & 97 & 97 & 0.46 \\
\hline Failed induction & 5 & 5 & 3 & $3 \%$ & NS \\
\hline \multicolumn{6}{|l|}{ Mode of delivery } \\
\hline Vaginal delivery & 80 & 84.21 & 77 & 79.38 & \multirow{2}{*}{$\begin{array}{l}0.496 \\
\text { NS }\end{array}$} \\
\hline Caesarean section & 15 & 15.79 & 20 & 20.62 & \\
\hline \multicolumn{6}{|c|}{ Induction delivery interval (time in hours) } \\
\hline $6-12$ & 27 & 28.42 & 26 & 26.80 & \multirow{4}{*}{$\begin{array}{l}0.352 \\
\text { NS }\end{array}$} \\
\hline$>12-18$ & 36 & 37.89 & 31 & 31.96 & \\
\hline $18-24$ & 32 & 33.68 & 40 & 41.24 & \\
\hline $\begin{array}{l}\text { Mean induction delivery } \\
\text { time }\end{array}$ & \multicolumn{2}{|c|}{$15.20 \pm 4.53$} & \multicolumn{2}{|c|}{$15.86 \pm 4.79$} & \\
\hline
\end{tabular}

Table 4: Indication for caesarean section and maternal side effects.

\begin{tabular}{|lllll|}
\hline Indication for caesarean & Group A & & Group B & Patients \\
\hline Meconium stained labour & Patients & $\mathbf{\%}$ & 7 & \% \\
\hline Non progress of labour & 4 & 26.6 & 5 & 25 \\
\hline Severe preeclampsia with HELLP & 3 & 20 & 0 & 0 \\
\hline Fetal distress & 2 & 13.33 & 8 & 40 \\
\hline Side effects & 6 & 40 & 6 & 6.06 \\
\hline Hypertonic uterus & & & 5 & 5.05 \\
\hline Nausea & 2 & 2.04 & 2 & 2.02 \\
\hline Postpartum haemorrhage & 3 & 3.06 & 1 & 1.01 \\
\hline Infection & 1 & 1.02 & 2.04 \\
\hline Fever, shivering & 2 & 2.04 & 6 & 6.06 \\
\hline Vomiting & 2 & 2.04 & & \\
\hline
\end{tabular}

Table 5: Neonatal complications and Apgar score.

\begin{tabular}{|c|c|c|c|c|c|}
\hline \multirow{2}{*}{ Neonatal complications } & \multicolumn{2}{|c|}{ Group A (n=95) } & \multicolumn{2}{|c|}{ Group B (n=97) } & \multirow{2}{*}{$P$ value } \\
\hline & Patients & $\%$ & Patients & $\%$ & \\
\hline Foetal distress & 6 & 6.32 & 8 & 8.25 & \multirow{4}{*}{$\begin{array}{l}0.238 \\
\text { NS }\end{array}$} \\
\hline Neonatal jaundice & 4 & 4.21 & 3 & 3.09 & \\
\hline Meconium aspiration & 2 & 2.11 & 2 & 2.06 & \\
\hline NICU Admission & 4 & 4.21 & 5 & 5.15 & \\
\hline \multicolumn{5}{|l|}{ Apgar score at 1 min } & \multirow{3}{*}{$\begin{array}{l}0.576 \\
\text { NS }\end{array}$} \\
\hline$<7$ & 5 & 5.2 & 7 & 7.2 & \\
\hline$>7$ & 90 & 94.7 & 90 & 92.7 & \\
\hline \multicolumn{5}{|l|}{ Apgar score at $5 \mathrm{~min}$} & \multirow{3}{*}{$\begin{array}{l}0.676 \\
\text { NS }\end{array}$} \\
\hline$<7$ & 2 & 2.1 & 3 & 3.09 & \\
\hline$>7$ & 93 & 97.8 & 95 & 97.9 & \\
\hline
\end{tabular}




\section{DISCUSSION}

Induction of labour with unfavourable cervix results in prolonged labour and increased rate of caesarean section. With time various methods of induction have come into practice. Each method has certain advantages and disadvantages inherent to it. It was found that in our study the mean of bishop's score in group A was $3.13 \pm 0.87$ and in group B was 3.36 \pm 0.91 which was comparable to the study by Dr. V Revathi in which the mean bishop score was $2.60 \pm 1.55$ in group $A$ and $2.86 \pm 1.57$ in group B (Table 6).

\section{Table 6: Comparison of bishop's score at start of induction.}

\begin{tabular}{|c|c|c|}
\hline $\begin{array}{l}\text { Author name and } \\
\text { year of study }\end{array}$ & Group A & Group B \\
\hline Revathi et al ${ }^{9}$ & $2.60 \pm 1.55$ & $2.86 \pm 1.57$ \\
\hline Alam et al $^{7}$ & $1.91 \pm 0.70$ & $1.90 \pm 0.77$ \\
\hline Murmu et $\mathrm{al}^{4}$ & $1.74 \pm 0.27$ & $1.48 \pm 0.82$ \\
\hline Present study & $3.13 \pm 0.87$ & $3.36 \pm 0.91$ \\
\hline
\end{tabular}

The main indication for induction of labour in Group A was Preeclampsia in $40 \%$ women and post-dated pregnancy in $29 \%$ which was also the main factor in other studies and the main indications for induction in Group B were Preeclampsia in $32 \%$ and post-dated pregnancy in $33 \%$ which were comparable with studies conducted by Anjumam Alam and Deshmukh V.L. (Table 7). The mean induction delivery interval in Group A was 15.20 \pm 4.53 hours while in Group B was $15.86 \pm 4.79$ hours. This shows that the induction delivery interval was equal in subjects who were induced with intracervical catheter and PGE2 gel.
The present study is consistent with studies done by Sunita Murmu and Deshmukh and various other studies also found this interval almost equal in both groups (Table 8).

The incidence of vaginal delivery in present study was $84.21 \%$ and caesarean study was $15.79 \%$ in Group A which was comparable with study done by Laddad, i.e., $82.5 \%$ and $17.5 \%$ respectively, by Dharmavijaya, it was $86 \%$ and $14 \%$ and by Sunita Murmu, it was $84.31 \%$ and $15.7 \%$ respectively (Table 9 ).

The NICU admissions in the groups A and B were less $(4.21 \%$ and $5.15 \%)$ respectively as compared to other studies. Complications in both the groups such as fetal distress and meconium aspiration syndrome were almost equal as the studies conducted by Manisha Laddad, Dharmavijaya and Deshmukh (Table 10).

The fetal outcome with apgar score $<7$ at 1 minute was comparable to various studies which was $10 \%$ in the study conducted by Dharmavijaya, $7.1 \%$ by Sunita Murmu and $5.2 \%$ in present study in group A. It was comparable to various studies in group B, which was $11 \%$ in study by Dharmavijaya, $8.6 \%$ by Sunita Murmu and $7.2 \%$ in our study. The fetal outcome with Apgar score $<7$ at 5 minutes was $1 \%$ in study conducted by Revathi in group A which was same as in our study (2.1\%). It was $7.5 \%$ in study by Deshmukh and $7 \%$ by Anjuman Alam which were different from the present study. The outcome with Apgar score $<7$ at $5 \mathrm{~min}$ in the present study in group B was $3.09 \%$ while it was $8 \%$ in the studies conducted by Deshmukh and Anjuman Alam. Limitation of the study was ours is a Government institute, PGE2 gel is sometimes not available freely due to limited supply.

So, this difficulty was faced while inducing the patients and it was bought by voluntary contribution to complete the study.

Table 7: Comparison of indication for induction of labour.

\begin{tabular}{|c|c|c|c|c|c|c|}
\hline & Group A & & & Group B & & \\
\hline Indication & $\begin{array}{l}\text { Present } \\
\text { study }(\%)\end{array}$ & $\begin{array}{l}\text { Deshmukh } \\
\text { et } \text { al }^{13}(\%)\end{array}$ & $\begin{array}{l}\text { Alam } \\
\text { et } \operatorname{al}^{7}(\%)\end{array}$ & $\begin{array}{l}\text { Present } \\
\text { study }(\%)\end{array}$ & $\begin{array}{l}\text { Deshmukh } \\
\text { et } \text { al }^{13}(\%)\end{array}$ & $\begin{array}{l}\text { Alam } \\
\text { et } \operatorname{al}^{7}(\%)\end{array}$ \\
\hline Pre-clampsia & 40 & 27.14 & 40 & 32 & 36.5 & 37 \\
\hline Postdatism & 29 & 29.5 & 32 & 33 & 31 & 30 \\
\hline Intrauterine fetal death & 4 & 6.5 & 6 & 6 & 8.5 & 7 \\
\hline Fetal growth restriction & 55 & 5 & 6 & 4 & 5.5 & 7 \\
\hline Oligohydramnios & 5 & 5 & 3 & 6 & 0.5 & 4 \\
\hline Polyhydramnios & 1 & - & - & - & - & - \\
\hline Antepartum eclampsia & 8 & - & - & 11 & - & - \\
\hline Others & 8 & 17 & 13 & 8 & 17 & 15 \\
\hline
\end{tabular}

Table 8: comparison of induction delivery interval of subjects in various studies.

\begin{tabular}{|c|c|c|}
\hline Name of author of study & Group A (hours) & Group B (hours) \\
\hline Deshmukh et al $^{13}$ & $15.32 \pm 5.24$ & $14.2 \pm 5.14$ \\
\hline Dharmavijaya et al ${ }^{10}$ & $15.32 \pm 5.24$ & $14.2 \pm 5.14$ \\
\hline
\end{tabular}




\begin{tabular}{|lll|}
\hline Name of author of study & Group A (hours) & Group B (hours) \\
\hline Jha et $^{\mathbf{1 1}}$ & $16.01 \pm 5.50$ & $16.85 \pm 3.81$ \\
\hline Alam et $\mathbf{~ a l}^{\mathbf{7}}$ & $16.01 \pm 5.50$ & $16.85 \pm 3.81$ \\
\hline Murmu et $\mathbf{a l}^{\mathbf{4}}$ & 12.2 & 15.47 \\
\hline Present study & $15.20 \pm 4.53$ & $15.86 \pm 4.79$ \\
\hline
\end{tabular}

Table 9: comparison of mode of delivery in subjects of group A in various studies.

\begin{tabular}{|c|c|c|}
\hline Name of Author of study & Vaginal delivery (\%) & Caesarean section (\%) \\
\hline 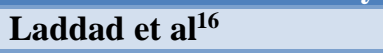 & 82.5 & 17.5 \\
\hline Dharmavijaya et $\mathrm{al}^{10}$ & 86 & 14 \\
\hline Murmu et al ${ }^{4}$ & 84.31 & 15.7 \\
\hline Present study & 84.21 & 15.79 \\
\hline
\end{tabular}

Table 10: Comparison of neonatal complications in various studies.

\begin{tabular}{|c|c|c|c|c|c|c|c|c|}
\hline \multirow[b]{2}{*}{$\begin{array}{l}\text { Name of } \\
\text { author and } \\
\text { year of study }\end{array}$} & \multicolumn{4}{|c|}{ Group A } & \multicolumn{4}{|c|}{ Group B } \\
\hline & $\begin{array}{l}\text { Fetal } \\
\text { distress } \\
(\%)\end{array}$ & $\begin{array}{l}\text { Neonatal } \\
\text { jaundice } \\
(\%)\end{array}$ & $\begin{array}{l}\text { Meconium } \\
\text { aspiration } \\
\text { syndrome } \\
(\%)\end{array}$ & $\begin{array}{l}\text { NICU } \\
\text { admission } \\
(\%)\end{array}$ & $\begin{array}{l}\text { Fetal } \\
\text { distress } \\
(\%)\end{array}$ & $\begin{array}{l}\text { Neonatal } \\
\text { jaundice } \\
(\%)\end{array}$ & $\begin{array}{l}\text { Meconium } \\
\text { aspiration } \\
\text { syndrome } \\
(\%)\end{array}$ & $\begin{array}{l}\text { NICU } \\
\text { admission } \\
(\%)\end{array}$ \\
\hline $\begin{array}{l}\text { Deshmukh } \\
\text { et al }{ }^{13}\end{array}$ & 8.5 & - & 4.5 & 18.5 & 10.5 & - & 5.5 & 21 \\
\hline Laddad et al $^{16}$ & 9 & - & 4 & 19 & 10.5 & - & 5 & 21.5 \\
\hline $\begin{array}{l}\text { Dharmavijaya } \\
\text { et } \text { al }^{10}\end{array}$ & 8.5 & - & 4.5 & 18.5 & 10.5 & - & 5.5 & 21 \\
\hline Present study & 6.23 & 4.21 & 2.11 & 4.21 & 8.25 & 3.09 & 2.06 & 5.15 \\
\hline
\end{tabular}

\section{CONCLUSION}

Our study concludes that there is no difference in efficacy between intracervical Foley's catheter and intracervical PGE2 gel for induction of labour. Also, other factors like induction delivery interval, maternal and neonatal outcomes were similar in both the groups. Both methods are complementary to each other

\section{ACKNOWLEDGMENTS}

It gives me immense pleasure to express my deepest sense of gratitude to my respected seniors and colleagues Dr. Khushpreet Kaur and Dr. Balwinder Kaur in carrying out this project. I am highly thankful for the guidance and encouragement given to me and appreciate the efforts put by my juniors for collecting the data and helping me in writing down this manuscript.

\section{Funding: No funding sources}

Conflict of interest: None declared

Ethical approval: The study was approved by the Institutional Ethics Committee

\section{REFERENCES}

1. Archie CL, Roman AS. Normal and abnormal labor and delivery. In: Alan H. DeCherney, Lauren Nathan, Neri Laufer, Ashley S. Roman, eds. Lange Current diagnosis and treatment in Obstetrics and
Gynaecology. 14th ed. USA: MC Graw Hill; 2013: 154-62.

2. ACOG Practice Bulletin No. 107: Induction of labor. Obstet Gynecol. 2009;114(2 Pt 1):386-97.

3. Carbone JF, Tuuli MG, Fogertey PJ, Roehl KA, Macones GA. Combination of Foley bulb and vaginal misoprostol compared with vaginal misoprostol alone for cervical ripening and labor induction: a randomized controlled trial. Obstet Gynecol. 2013;121(2 Pt 1):247-52.

4. Sunita Murmu, Chetna Dwivedi. A Comparative Study of Intracervical Foley's Catheter and intracervical PGE2 gel for pre-induction cervical ripening. International Journal of reproduction, contraception obstetrics and Gynecology. Int J Reprod Contracept obstet Gynecol. 2018;7(8):3122-25.

5. Mahendroo M. Cervical remodeling in term and preterm birth: insights from an animal model. Reproduction. 2012;143(4):429-38.

6. Jozwiak M, Bloemenkamp KW, Kelly AJ, Mol BW, Irion $\mathrm{O}$, Boulvain M. Mechanical methods for induction of labour. Cochrane Database Syst Rev. 2012;(3):001233.

7. Alam A, Ahmed EA. A comparative study of intracervical foley's catheter and PGE2 gel for preinduction cervical ripening. Int J Reprod Contracept Obstet Gynecol. 2016;5:2644-7.

8. Cunningham FG, Leveno KJ, Bloom SL, Hauth JC, Rouse DJ, Spong CY. Induction and augmentation of 
labour. Williams textbook of obstetrics. 24th ed. MC Graw Hill; 526.

9. Revathi V, Archana I. A comparative study of efficacy of intracervical prostaglandin E2 gel and intracervical foleys catheter for preinduction cervical ripening. IOSR J of dental and med sci. 2015;14(4):42-6.

10. Vijaya Mn D, Umashankar K, Sudha, Nagure AG, Kavitha G. Prevalence of the trichomonas vaginalis infection in a tertiary care hospital in rural bangalore, southern India. J Clin Diagn Res. 2013;7(7):1401-3.

11. Jha Richa, Rohatgi R. Comparative Study of Intracervical Foleys Catheter Instillation vs PGE2 Gel for Induction of Labour. International J Sci Res. 2017;6(5):1915-8.

12. Rachel Alexander A, Gigi A. Comparative study on cervical ripening and labour induction with dinoprostone versus foley's catheter with extra amniotic saline infusion. Int $\mathrm{J}$ Reprod Contracept Obstet Gynecol. 2020;9(10):4080-85.

13. Deshmukh VL, Yelikar KA, Deshmukh AB. Comparative Study of Intra-cervical Foley's Catheter and PGE(2) Gel for Pre-induction Ripening (Cervical). J Obstet Gynaecol India. 2011;61(4):418-21.

14. Nayak S, Pati D, Sahu N, Venkatarao E, Sahu MC, Marandi S, Mohapatra S. Role of intracervical dinoprostone gel administration versus vaginal administration of oral prostaglandin E2 tablet for induction of labour. Int $\mathbf{J}$ pharm Sci Rev Res. 2015;30(1):1-6.

15. Geetha P. Induction of labour with prostaglandin E2 vaginal gel in women with one previous caesarean section. Middle East Fertility Society J. 2012;17:170-5.

16. Laddad MM, Kshrisagar NS, Anand V, Karale. A prospective randomized comparative study of intracervical ripening. International $\mathrm{J}$ of Reproduction, Contraception, Obstetrics and Gynaecology. Int J Reprod Contracept Obstet Gynecol. 2013;2(2):217-20.

17. Kadam D, Kshirsagar S, Patil Sanjay, Patil Yamini. Comparative study of extra amniotic foleys catheter and intracervical PGE 2 gel for pre - labour cervical ripening. Journal of Evolution of Medical and Dental Sciences. 2015;236:1672-80.

Cite this article as: Kaur K, Kaur B, Kaur N, Kaur G Intra-cervical Foley's catheter or PGE2 gel for induction of labour: which one is better- a prospective study. Int J Reprod Contracept Obstet Gynecol 2021;10:1802-8. 